\title{
VacA pores as portable portals for urea
}

\author{
Juanita L. Merchant
}

Internal Medicine and Physiology, University of Michigan, 1150 West Medical Center Drive, MSRB I, Room 3510, Ann Arbor, Michigan 48109-0650, USA.

Phone: (734) 647-2944; Fax: (734) 936-1400; E-mail: merchanj@umich.edu.

J. Clin. Invest. 108:803-804 (2001). DOI:10.1172/JCI200114004.

The epithelial linings of various organs have evolved to shield us from harmful aspects of our environment. In the stomach, the epithelial lining provides a reliable barrier against ingested microbes and toxins, in part by secreting copious amounts of gastric acid, whose major function is to sterilize the stomach contents (1). Whereas most microorganisms, peptides, and toxins cannot survive the low $\mathrm{pH}$ of the human stomach, the gastric epithelium has evolved to tolerate this environment, as have certain gastric bacteria, not all of which are benign.

Ulceration of the gastric mucosa was long attributed to excessive acid secretion triggered by stress, and the contribution of microorganisms was overlooked. More recently, it has been revealed that ulcers, like so many other diseases to which humans succumb, are primarily an infectious disorder (2). Nearly 20 years ago, when this hypothesis was confirmed (3), the idea that bacterial infection causes ulcers was considered heresy since no one believed that any organism could survive a $\mathrm{pH}$ less than 2 . Warren and Marshall clearly demonstrated, however, and survive at low $\mathrm{pH}$ or might trigger inflammation in the infected stomach. VacA, a toxin expressed by most clinical isolates of H. pylori, meets both criteria. Coincubation of recombinant VacA protein with gastric cell lines induces vacuole formation in the cytoplasm (4), and VacA-expressing strains appear to colonize the stomach more efficiently (5). However, isogenic vacA mutants can colonize and trigger gastritis in both gnotobiotic piglets and Mongolian gerbils $(6,7)$. Thus, while VacA is clearly a type of virulence factor, it does not appear to be absolutely required for $H$. pylori virulence.

VacA is expressed as a $140-\mathrm{kDa}$ precursor that is processed to a functional 94-kDa toxin. Following export and exposure to acid, this toxin assembles spontaneously into oligomers. Three domains are required for its activity: a 33-amino acid $\mathrm{N}$-terminal signal sequence, which is cleaved from the mature protein but is required to direct the toxin to the periplasm; an $\mathrm{N}$ terminal 37-kDa region, which contains the vacuolating activity; and a Cterminal $58-\mathrm{kDa}$ region, which is required for binding of the protein to
A common mechanism for pathogens that damage target cells without direct bacterial invasion is the ability to produce factors that punch holes through the host cell membrane.

that Helicobacter pylori thrives at low $\mathrm{pH}$, and this bacterium is now known to be the major mechanism by which ulcers of the upper gastrointestinal tract are induced.

The question that remains unanswered is how $H$. pylori stimulates acid secretion and induces chronic gastritis. Initial studies identified several bacterial gene products that either are required for the organism to colonize target cell membranes (8). Polymorphisms in VacA account for much of the variation among clinical isolates that can be distinguished antigenically (9). Numerous reports correlate the different isoforms of VacA with virulence. In contrast, another major $H$. pylori virulence factor, CagA, requires accessory factors expressed from the cag pathogenicity island to mediate its attack on cells. Several studies have now reported that CagA is translocated into the cytoplasm by a type IV secretory apparatus and is subsequently phosphorylated by host cell factors (10-13).

In this issue of the JCI, Tombola and colleagues report a specific function for VacA in the pathogenesis of stomach ulcers (14). They show here that $H$. pylori VacA binds preferentially to the apical plasma membrane, permeabilizing the host cell to urea. VacA therefore acts as a low $\mathrm{pH}$-activated transmembrane pore. In addition to allowing the transport of neutral solutes, it may also allow the transport of electrolytes and therefore compromise the ability of the host cell to regulate its intracellular environment. While this process is toxic to the host epithelial cell, as evidenced by vacuole formation, VacA provides the bacterium with a competitive advantage by increasing the availability of urea. This metabolite can be converted to ammonia by the cytoplasmic enzyme urease in a reaction regulated by the protongated urea channel UreI. Because the accumulation of ammonia increases the buffering capacity within the periplasmic space (15), it appears that VacA improves the efficiency of a $\mathrm{pH}$ sensitive homeostatic mechanism.

Unlike CagA, which requires an elaborate pore-forming structure to traverse the lipid bilayer, VacA can form pores in lipid bilayers autonomously, which classifies the toxin as a type $\mathrm{V}$ autotransporter pore (16). A common mechanism for pathogens that damage target cells without direct bacterial invasion is the ability to produce factors that punch holes through the host cell membrane, either by acting alone or by assembling a multi-subunit apparatus (16). These structures permit the flow of solutes from the environment through the outer and inner membranes of the bacteria, but they also disrupt the ability of the tar- 
get cell to maintain integrity and homeostasis. Whether this is advantageous to the bacterium is unclear, since in many instances, the loss of cell integrity eventually cripples the cell. In response, the injured cell secretes chemokines that activate immune cells to attack the luminal pathogen.

Studies of Helicobacter infection in $\mathrm{T}$ or B cell-deficient mice show that Th1 cells, but not B lymphocytes, are required for the onset of gastritis (17, 18). Therefore, analogous to inflammatory bowel disease, which primarily affects the small and large bowels, smoldering inflammation in the stomach also appears to be responsible for the chronic tissue damage and neoplastic sequelae. Loss of differentiated cell types such as parietal and chief cells after months to years of cohabitation with the organism eventually compromises the stomach's capacity to secrete acid and leads to a rise in gastric $\mathrm{pH}$.

It is not obvious how loss of parietal cells and the eventual rise in gastric $\mathrm{pH}$ might benefit the bacteria. Although this has not been tested directly, it seems unlikely that $H$. pylori can colonize the gastric epithelium efficiently in the absence of acid $(15,19)$. Reduced colonization may be due to insufficient gastric acid to counterbalance the ammonia produced by the organism. Moreover, with a rise in $\mathrm{pH}$, the stomach is at risk of colonization by less fastidious bacterial species, which may then out-compete $H$. pylori $(20,21)$. Thus, in the end, $H$. pylori may merely be the trigger for a cascade of events that is sustained by the immune system and by repopulation of the stomach by organisms other than $H$. pylori.

While most $H$. pylori strains express $v a c A$, there is poor correlation of $v a c A$ status with clinical disease and outcome in non-US populations $(22,23)$. Asian and other non-Western popula- tions make up a large proportion of the world's population infected with H. pylori ( $50 \%)$. Moreover, in vitro studies demonstrate that VacA protein is not required to induce an inflammatory response and colonize animal models $(6,24)$, implying that non-VacA $H$. pylori strains must be able to transport urea effectively to survive in the acidic stomach. Since vacA mutants obviously still colonize the normal acid-secreting stomach, it may be that other pore-forming molecules perform an analogous function in these strains (25). The identification of other such proteins may be needed for vaccine development, since it is probable that targeting VacA alone will not generate a universal vaccine (26). Rather, a cocktail of multiple $H$. pylori-specific factors will likely be required.

1. Gray, J.D., and Shiner, M. 1967. Influence of gastric $\mathrm{pH}$ on gastric and jejunal flora. Gut. 8:74-81.

2. Blaser, M.J. 1996. The bacteria behind ulcers. Sci. Am. 274:104-107.

3. Marshall, B.J., and Warren, J.R. 1984. Unidentified curved bacilli in the stomach of patients with gastritis and peptic ulceration. Lancet. 1:1311-1315.

4. Cover, T.L., and Blaser, M.J. 1992. Purification and characterization of the vacuolating toxin from Helicobacter pylori. J. Biol. Chem. 267:10570-10575.

5. Salama, N.R., Otto, G., Tompkins, L., and Falkow S. 2001. Vacuolating cytotoxin of Helicobacter pylori plays a role during colonization in a mouse model of infection. Infect. Immun. 69:730-736

6. Eaton, K.A., Cover, T.L., Tummuru, M.K., Blaser, M.J., and Krakowka, S. 1997. Role of vacuolating cytotoxin in gastritis due to Helicobacter pylori in gnotobiotic piglets. Infect. Immun. 65:3462-3464

7. Wirth, H.P., Beins, M.H., Yang, M., Tham, K.T. and Blaser, M.J. 1998. Experimental infection of Mongolian gerbils with wild-type and mutant Helicobacter pylori strains. Infect. Immun. 66:4856-4866

8. de Bernard, M., et al. 1998. Identification of the Helicobacter pylori VacA toxin domain active in the cell cytosol. Infect. Immun 66:6014-6016.

9. Atherton, J.C., et al. 1995. Mosaicism in vacuolating cytotoxin alleles of Helicobacter pylori. Association of specific vacA types with cytotoxin production and peptic ulceration. J. Biol. Chem. 270:17771-17777.

10. Asahi, M., et al. 2000. Helicobacter pylori CagA protein can be tyrosine phosphorylated in gastric epithelial cells. J. Exp. Med. 191:593-602.

11. Backert, S., et al. 2000. Translocation of the Helicobacter pylori CagA protein in gastric epithelia cells by a type IV secretion apparatus. Cell. Microbiol. 2:155-64.

12. Odenbreit, S., et al. 2000. Translocation of Helicobacter pylori CagA into gastric epithelial cells by type IV secretion. Science. 287:1497-1500.

13. Stein, M., Rappuoli, R., and Covacci, A. 2000 Tyrosine phosphorylation of the Helicobacter pylori CagA antigen after cag-driven host cell translocation. Proc. Natl. Acad. Sci. USA. 97:1263-1268

14. Tombola, F., et al. 2001. The Helicobacter pylor VacA toxin is a urea permease that promotes urea diffusion across epithelia. J. Clin. Invest. 108:929-937.

15. Meyer-Rosberg, K., Scott, D.R., Rex, D., Melchers, K., and Sachs, G. 1996. The effect of environmental $\mathrm{pH}$ on the proton motive force of Helicobacter pylori. Gastroenterology. 111:886-900.

16. Henderson, I.R., and Nataro, J.P. 2001. Virulence functions of autotransporter proteins. Infect. Immun. 69:1231-1243.

17. Smythies, L.E., et al. 2000. Helicobacter pyloriinduced mucosal inflammation is Th1 mediated and exacerbated in IL-4, but not IFN-gamma, gene-deficient mice. J. Immunol. 165:1022-1029.

18. Lohoff, M., Rollinghoff, M., and Sommer, F. 2000. Helicobacter pylori gastritis: a Th1 mediated disease? J. Biotechnol. 83:33-36.

19. Eaton, K.A., and Krakowka, S. 1995. Avirulent, urease-deficient Helicobacter pylori colonizes gastric epithelial explants ex vivo. Scand. J. Gas troenterol. 30:434-437.

20. Mowat, C., et al. 2000. Omeprazole, helicobacter pylori status, and alterations in the intragastric milieu facilitating bacterial N-nitrosation. Gas troenterology. 119:339-347.

21. Sanduleanu, S., Jonkers, D., De Bruine, A., Hameeteman, W., and Stockbrugger, R.W. 2001. Non-Helicobacter pylori bacterial flora during acid-suppressive therapy: differential findings in gastric juice and gastric mucosa. Aliment. Phar macol. Ther. 15:379-388.

22. Shimoyama, T., et al. 1999. VacA seropositivity is not associated with the development of gastric cancer in a Japanese population. Eur. J. Gastroen terol. Hepatol. 11:887-890.

23. Yamaoka, Y., et al. 1999. Relationship between Helicobacter pylori iceA, cagA, and vacA status and clinical outcome: studies in four different countries. J. Clin. Microbiol. 37:2274-2279.

24. Mitsuno, Y., et al. 2001. Helicobacter pylori induced transactivation of SRE and AP-1 through the ERK signalling pathway in gastric cancer cells. Gut. 49:18-22.

25. Hancock, R.E., Alm, R., Bina, J., and Trust, T. 1998. Helicobacter pylori: a surprisingly con served bacterium. Nat. Biotechnol. 16:216-217.

26. Del Giudice, G., Covacci, A., Telford, J.L., Montecucco, C., and Rappuoli, R. 2001. The design of vaccines against Helicobacter pylori and their development. Annu. Rev. Immunol. 19:523-563. 